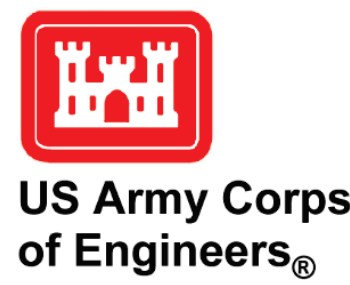

\title{
AIS Data Case Study: Evaluating Reception of AIS Position Reports on the Missouri River by LOMA AIS Sites in April and August 2020
}

\author{
by Brian J. Tetreault, Marin M. Kress, Patricia K. DiJoseph
}

PURPOSE: This Coastal and Hydraulics Engineering Technical Note (CHETN) describes a method for evaluating the received coverage from Automatic Identification System (AIS) shoreside sites along the Missouri River managed by the US Army Corps of Engineers (USACE) Lock Operations Management Application (LOMA), and presents the results of that analysis. The purpose is to identify AIS coverage gaps in the current system. Reception of AIS transmissions between shore-based transceivers and vessels is generally line-of-sight between the vessel and the AIS site antenna. However, signal reception may be affected by factors such as the distance and terrain between the vessel and the transceiver site, quality of the transceiver installation, state of the equipment either aboard the vessel or at the shore transceiver station, and atmospheric phenomena. Quantifying coverage gaps along the inland waterways system can inform research that uses AIS data, provide information on the performance of the AIS network, and provide guidance for efforts to address coverage gaps to improve navigation safety. In autumn 2020, severe shoaling was occurring on the Missouri River. As the shoals were identified, the Kansas City District requested the LOMA system transmit AIS Aid to Navigation (AtoN) to mark the shoals in several critical areas. However, vessel pilots sometimes reported that they were not receiving the AIS AtoN being transmitted. At the request of the Kansas City District, the US Army Engineer Research and Development Center, Coastal and Hydraulics Laboratory (ERDC-CHL), conducted a coverage analysis using data collected from the LOMA AIS transceivers in the area to determine if there were coverage issues and their extent and to aid in determining the best means of addressing any coverage gaps.

INTRODUCTION: The availability of historical vessel position reports from the US Coast Guard (USCG) Nationwide Automatic Identification System (NAIS) archive (USCG 2018) has dramatically improved the ability to examine how commercial vessels use navigable waterways (DiJoseph et al. 2019; Mitchell and Scully 2014; Scully and Mitchell 2015) to inform freight demand models (Asborno et al. 2020) and has provided waterway managers with a valuable tool for understanding their local navigation traffic (Kress et al. 2020; Mitchell et al. 2020; Tabbert et al. 2020). Since 2016, AIS carriage requirements include most commercial self-propelled vessels on US navigable waterways including any vessel over $65 \mathrm{ft}^{1}$ in length, towing vessels over $26 \mathrm{ft}$ in length with a greater than 600 hp engine, vessels certified to carry 150 or more passengers, dredges in or near a commercial channel, and vessels moving certain dangerous cargo (USCG 2018; US Code of Regulations 2019). AIS technical standards and history can be found online through international associations involved in setting technical standards (IALA 2008; IEC 2001; ITU-R 2014; PIANC 2019). The USACE LOMA system provides primary AIS coverage on inland waterways, and AIS messages received by LOMA AIS shore sites are routed to the USCG where they are archived with other signals received

\footnotetext{
${ }^{1}$ For a full list of the spelled-out forms of the units of measure used in this document, please refer to US Government Publishing Office Style Manual, $31^{\text {st }}$ ed. (Washington, DC: US Government Publishing Office, 2016), 248-52, https://www.govinfo.gov/content/pkg/GPO-STYLEMANUAL-2016/pdf/GPO-STYLEMANUAL2016.pdf
} 
by NAIS for long-term storage. The LOMA system also archives data for short term use ( $\sim 45$ days), and raw received data are archived on the local site controllers for many LOMAAIS sites.

AIS operates using the very high frequency (VHF) radio spectrum, operating on $161.975 \mathrm{MHz}$ and 162.025 MHz. VHF transmissions are generally line-of-sight (i.e., the antenna of the transmitting station must have an unobstructed path to the receiving station's antenna). The transmission may be attenuated or blocked by the earth (radio horizon based on antenna heights or terrain) or structures. The signal may also be reduced by other factors, such as transmission power, equipment condition, and quality of installation. Therefore, not all AIS signals transmitted by vessels are received by shore AIS stations and vice versa. Vessels transmit AIS position reports depending on their dynamic condition (Table 1) where the frequency varies from $2 \mathrm{sec}$ up to $3 \mathrm{~min}$. Vessel AIS stations can transmit other types of messages, but this work focused on position reports transmitted by vessel AIS stations.

\begin{tabular}{|l|l|}
\hline \multicolumn{2}{|l|}{ Table 1. Class A shipborne mobile equipment reporting intervals. } \\
\hline Ship's dynamic conditions & Nominal reporting interval \\
\hline Ship at anchor or moored and not moving faster than 3 kn & $3 \mathrm{~min}$ \\
\hline Ship at anchor or moored and moving faster than 3 kn & $10 \mathrm{sec}$ \\
\hline Ship 0-14 kn & $10 \mathrm{sec}$ \\
\hline Ship 0-14 kn and changing course & $31 / 3 \mathrm{sec}$ \\
\hline Ship 14-23 kn & $6 \mathrm{sec}$ \\
\hline Ship 14-23 kn and changing course & $2 \mathrm{sec}$ \\
\hline Ship $>23 \mathrm{kn}$ & $2 \mathrm{sec}$ \\
\hline Ship $>23 \mathrm{kn}$ and changing course & $2 \mathrm{sec}$ \\
\hline
\end{tabular}

Source: ITU-R M.1371-5, 2014, page 8.

The LOMA program operates over 150 AIS transceivers located primarily along the inland waterways of the United States. These transceivers receive transmissions from AIS-equipped vessels transiting these waters and also transmit information to vessels to be used for safe navigation, including AIS AtoN. There are three LOMA AIS sites along the Missouri River (Figure 1). There are two sites on the Illinois and Mississippi Rivers that cover portions of the lower Missouri River. Table 2 lists the location and antenna height in meters for each of the sites while Figure 1 shows the sites on a map.

Table 2. AIS site name, antenna height, and river mile location.

\begin{tabular}{|l|l|l||}
\hline AIS Site Name & $\begin{array}{l}\text { Antenna height above ground } \\
\text { in meters }(\mathbf{m}),(\mathrm{ft})\end{array}$ & $\begin{array}{l}\text { Missouri river mile (river mile, } \\
\text { other river) }\end{array}$ \\
\hline Lexington & $91.4 \mathrm{~m}(299.8 \mathrm{ft})$ & 319 \\
\hline Glasgow & $123.4 \mathrm{~m}(404.8 \mathrm{ft})$ & 227 \\
\hline Gasconade & $91.4^{*} \mathrm{~m}(299.8 \mathrm{ft})$ & 104 \\
\hline Pere Marquette & $30.5 \mathrm{~m}(100 \mathrm{ft})$ & $24(8$, Illinois River $)$ \\
\hline Melvin Price Lock and Dam & $6.1 \mathrm{~m}(20 \mathrm{ft})$ & $3(201$, Mississippi River $)$ \\
\hline
\end{tabular}

${ }^{\star}$ The antenna at the Gasconade site was lower (at less than $5 \mathrm{~m}$ above the ground) until June 2020. 


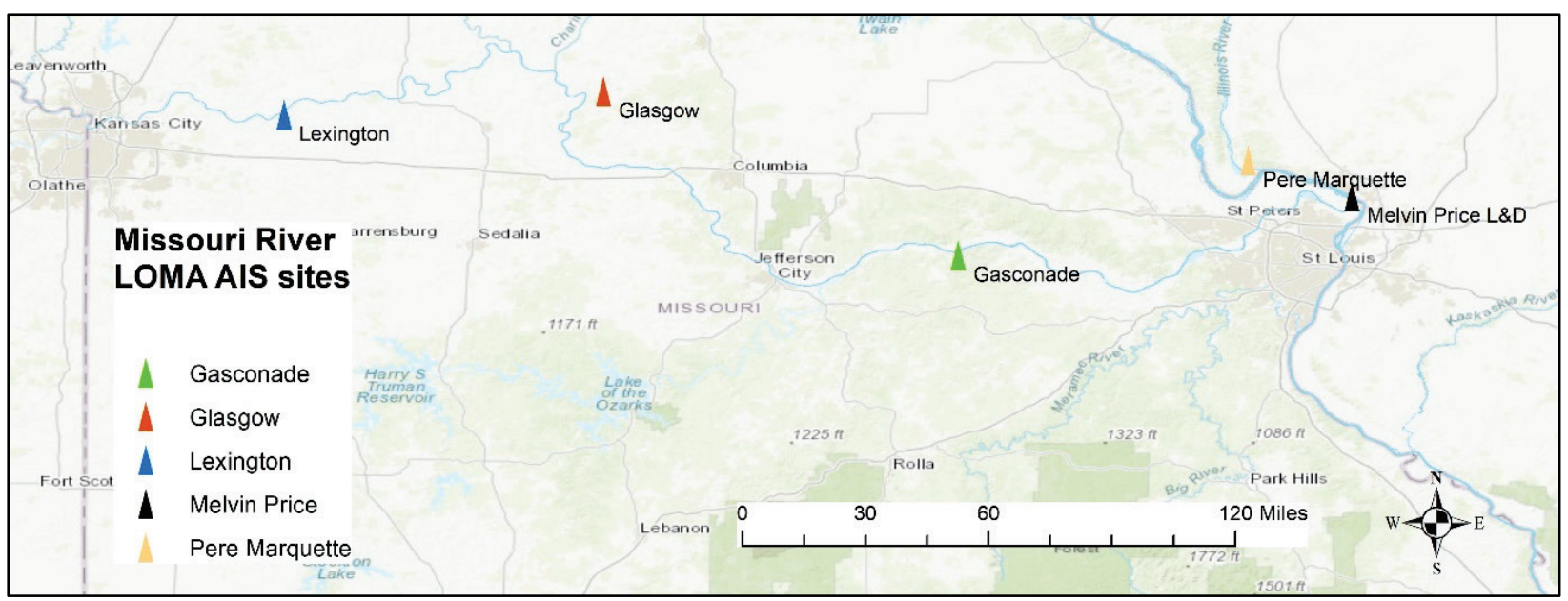

Figure 1. Three LOMAAIS sites along Missouri River and two along the Mississippi River.

METHOD: The data used for this study consisted of AIS position reports received by each site for the month of April 2020 except for the Gasconade site. At the Gasconade site, data from August 2020 were used because in early summer 2020 the antenna height was increased and subsequently improved coverage, but this information was not discovered until after the analysis was complete for other sites. The data set included 1,758,819 position reports from 133 unique vessels. The raw AIS data (retrieved from the site controllers) was parsed using the USCG-provided AISMiner application (USCG Research and Development Center 2014). The parsed data were imported into ArcMap 10.7.1 software package (ESRI 2019), filtered to include only position reports on the Missouri River, and plotted to show the extent of the coverage area for each site (see Results section, Figure 3). The Missouri River was segmented into $1 \mathrm{mi}$ long polygons (reaches) using the eHydro National Channel Framework (NCF) (USACE 2021).

There were five key assumptions in this study. (1) AIS data received from vessels at transceiver locations ("talk in") were equivalent to transmissions from transceivers received by vessels ("talk out"). (2) One month of AIS data is adequate to perform an initial coverage analysis. (3) All reaches in the study area (mile 0-460) had at least one AIS-equipped vessel transit through them in April 2020. (4) Vessels transited at the observed average speed continuously through the reach, as calculated from AIS signals within the reach. Although this is unlikely given dynamic river conditions, it is a reasonable assumption for vessels that transit a reach as through-traffic without stopping or maneuvering in the reach. There are several reaches where this assumption clearly does not hold, and these reaches have unusually high position report counts. (5) Last, reports from one vessel in a reach were from one transit through that reach. While this assumption is known to be erroneous, there is additional work underway to write scripts to automate a method to calculate vessel transit counts. Using the data and assumptions listed above, two methods were used to describe AIS coverage.

Method 1: Vessel Position Reports Received by LOMA AIS Transceivers. This method utilized a count of the position reports received per Missouri River reach geospatial area (defined within the (USACE 2021), usually $1 \mathrm{mi}$ long segments stretching across the river from bank to bank). To identify areas of overlapping coverage, the total number of position reports received within a given river reach by each site were plotted (see Results, Figure 4).

Method 2: Number of Expected vs. Received Vessel Position Reports within a Reach Based on Vessel Speed. This second method compared the actual number of position reports 
received by each site within a 1 mi waterway reach against the expected number of position reports for that reach based on the average vessel speed as reported through the AIS messages received from vessels. Since shipboard AIS equipment transmits position reports at a predictable rate, approximately once every $10 \mathrm{sec}$ (Table 1), it is possible to calculate the expected number of position reports that a vessel will broadcast within a $1 \mathrm{mi}$ reach when traveling at a given speed. A graph of expected position reports per mile (assuming a $10 \mathrm{sec}$ broadcast frequency) vs. vessel speed is shown in Figure 2. The average speed of each vessel while traveling through each 1 mi reach was calculated by averaging the speed-over-ground data that are included in an AIS message for all position reports. Not all vessels were present in all reaches. Some vessels made multiple transits through a reach in a given month, but as stated above (see assumption \#5) for this initial study, all reports from a single vessel were aggregated to make one average speed calculation per vessel, per $1 \mathrm{mi}$ reach, per month. Then, that average speed was used to identify the expected number of position reports per vessel, per reach. This expected position report count was compared to the actual count received and a "percentage of expected reports received" value was calculated per vessel, per reach. In some reaches, the percentage of expected reports received was well over $100 \%$ due to vessels that remained in the reach for significant amounts of time. This over counting could be addressed in the future by obtaining an accurate count of the actual number of vessel transits through a particular reach during the study period and by eliminating slow-moving vessels and vessels that operate only within a small number of reaches.

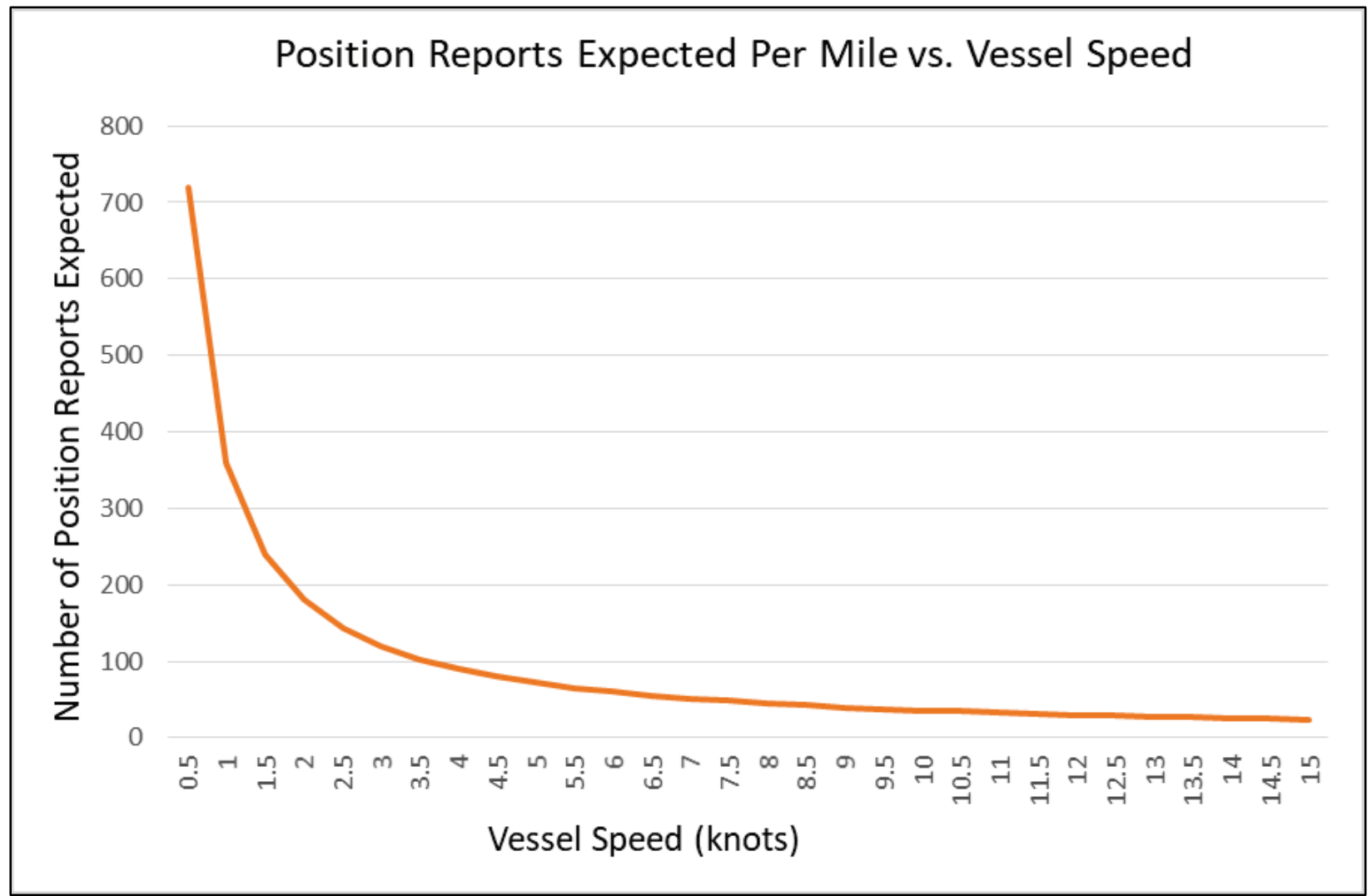

Figure 2. Expected position reports per mile as a function of vessel speed. 


\section{RESULTS}

Coverage Measure 1: Vessel Position Reports Received by LOMA AIS Transceivers. AIS position reports received by each site are plotted on a map in Figure 3. This provides an initial indication of the spatial coverage from each site along the Missouri River from river mile 0 to 500 and provides an indication of areas of no coverage (most visible as gaps in the dark blue lines on the left end of the map near Leavenworth, KS). Detailed spatial coverage results are shown in Figure 5 through Figure 8. Missouri River mile 0 is at the confluence with the Mississippi River (near Melvin Price L\&D on Figure 3), river mile 500 is just upriver from St. Joseph, MO, on the farleft side of Figure 3. Although Figure 3 provides an indication of the spatial reach of tower coverage, it does not provide an indication of the quality of the coverage, only that at least one position report was received during the study period (i.e., 1 month). Simply receiving a position report does not provide assurance that transmissions from the LOMA transceivers could be received by a vessel at that location. In contrast, if the plotting reveals there are no position reports received for a waterway segment by a LOMA transceiver, it is a good indication that transmissions from a LOMA AIS transceiver will not be received by vessels in that area.

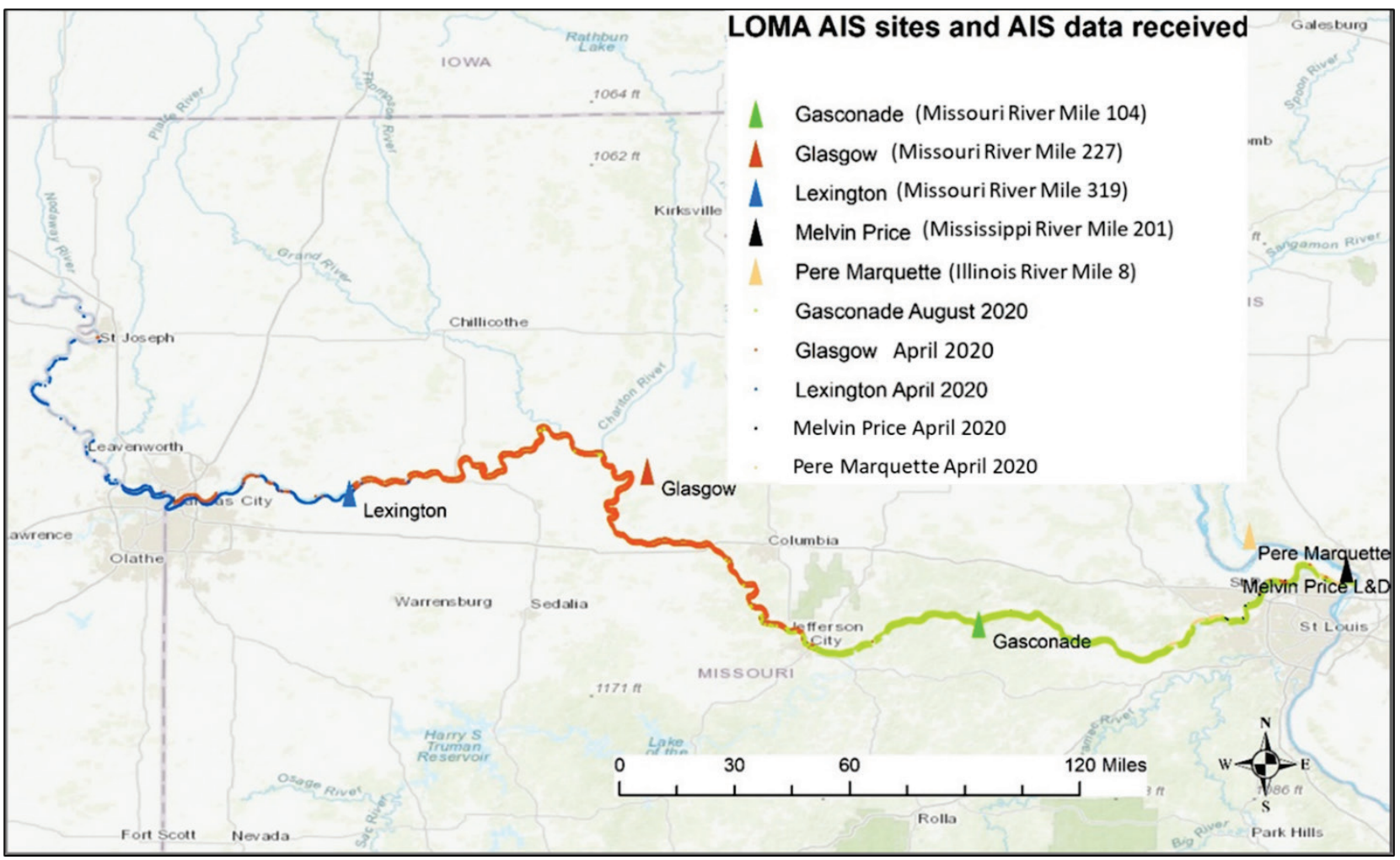

Figure 3. Plot of all vessel position reports received along the Missouri River by LOMAAIS transceiver sites.

Figure 4 shows the number of position reports received in each channel reach for April 2020, except for the Gasconade site, which uses data received from that site for August 2020. Stacked color bars indicate that more than one LOMA site received position reports from that reach. Although vessel transmissions from a single river reach may reach more than one LOMA site, there is usually one site that has better reception for that reach. 


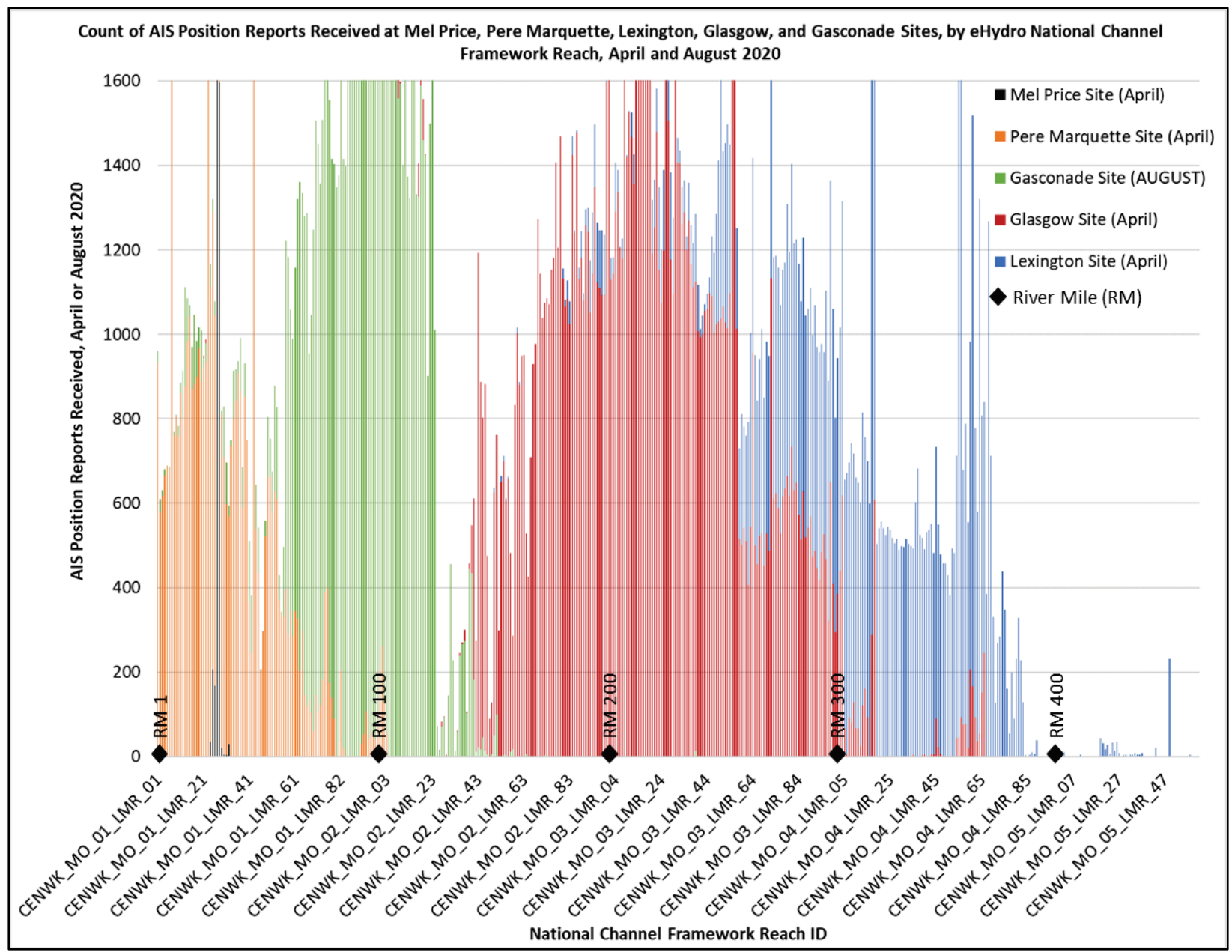

Figure 4. Number of vessel position reports received per Missouri River channel reach by LOMAAIS transceiver sites April 2020 and August 2020 (Gasconade only). The y-axis truncated at 1600.

\section{Coverage Measure 2: Number of Expected vs. Received Vessel Position Reports} within a Reach Based on Vessel Speed. The expected count of vessel position reports was compared to the actual count received, and a percentage of expected reports received value was calculated for each reach. This number was calculated per vessel, per reach.

These results were used to categorize each reach into one of five possible categories: zero position reports, $0 \%-25 \%, 25 \%-50 \%, 50 \%-75 \%$, and greater than $75 \%$ expected reception of position reports. These results are shown in Figure 5 through Figure 8 for the aggregate expected reception on the entire river below mile 460 .

In Figure 5 through Figure 8, the following colors are used to represent the coverage quality, which is characterized as "No coverage," "Marginal," "Poor," "Fair," or "Good":

- Red indicates zero percent of expected reports were received - No coverage

- Orange indicates $>0 \%$ to $25 \%$ of expected received - Marginal coverage

- $\quad$ indicates $>25 \%$ to $50 \%$ of expected received - Poor coverage

- Light indicates $>50 \%$ to $75 \%$ of expected received - Fair coverage

- Dark Green indicates $>75 \%$ of expected received - Good coverage. 
Aggregate Results. Figure 5 through Figure 8 show sections of the Missouri River color-coded by reach to illustrate the maximum percentage of expected AIS position reports received for that reach across all LOMA sites. Following each figure is a narrative summary of the aggregate coverage for the river miles shown.

Figure 5 shows that there is good coverage between mile 0 and 100, with a few fair coverage areas around miles 47, 48, and 56 .

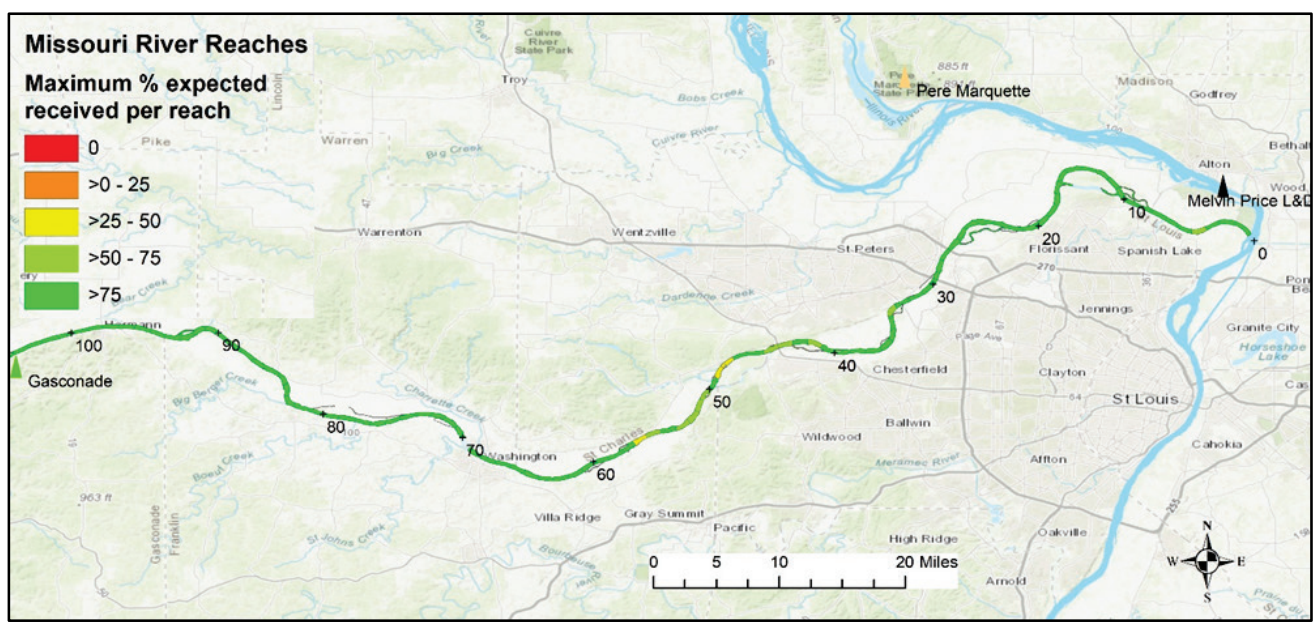

Figure 5. Aggregate coverage, mile 0-100.

Figures 5 and 6 show good coverage between miles 100 and 240 except for several gaps (marginal and poor coverage) between miles 125 and 139. There is an area of poor coverage at miles 149-150.

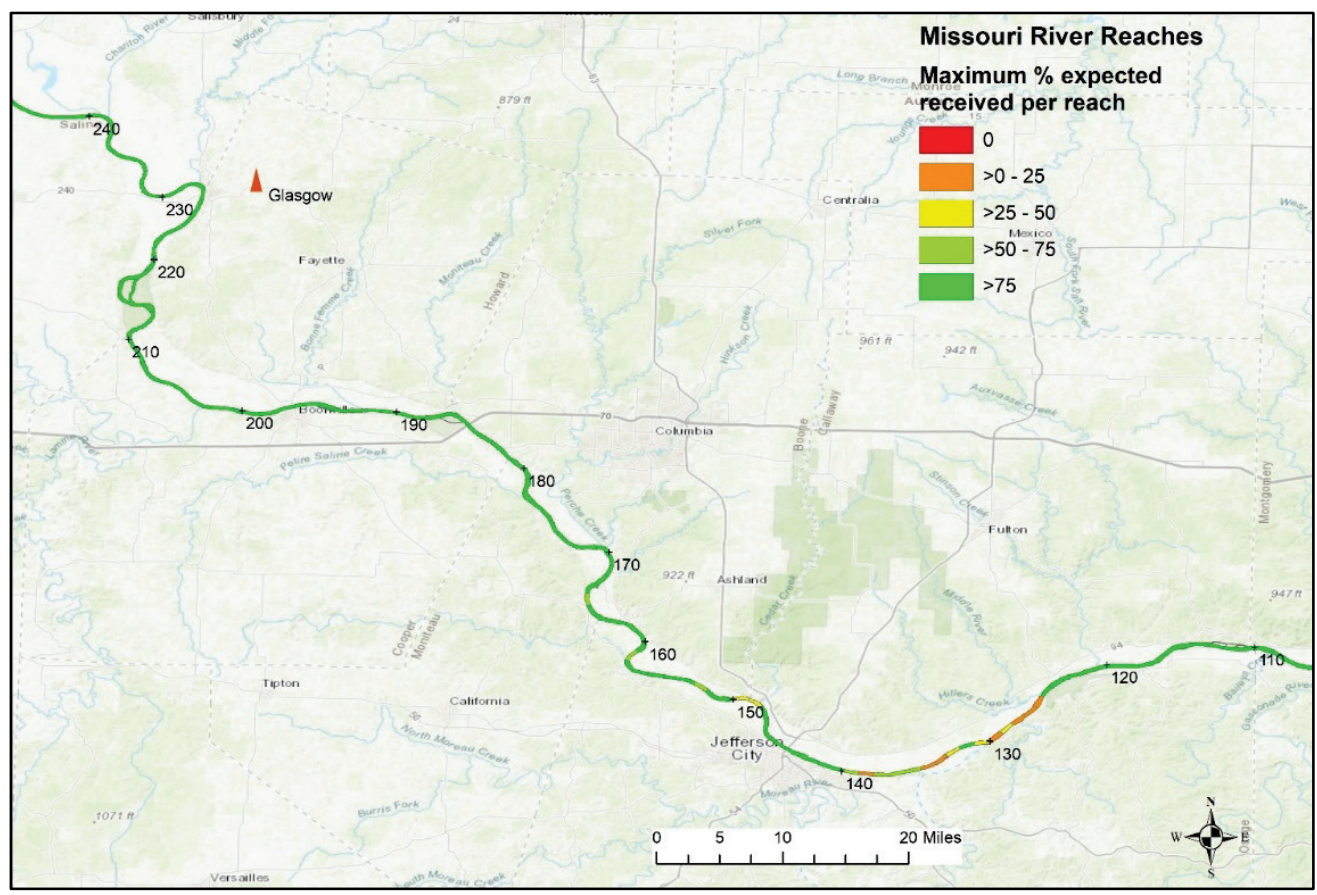

Figure 6. Aggregate coverage, mile 110-240 (mile marker 100 shown in Figure 5). 
Figure 7 shows that there is consistently good coverage between miles 240 and 340 .

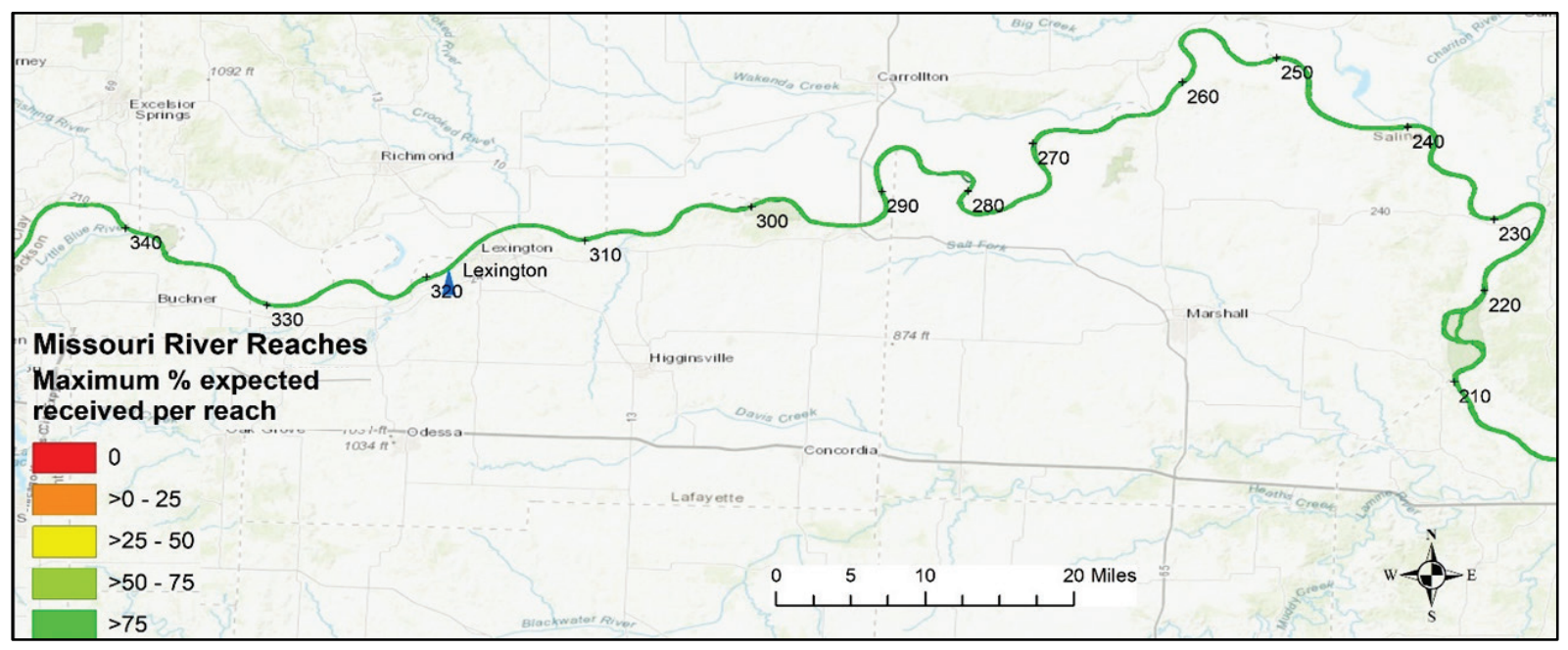

Figure 7. Aggregate coverage, mile 210-340.

Figure 8 shows that there is good coverage from mile 330 through mile 382 , with one area of marginal coverage at mile 376 . Above mile 382 , coverage is sporadic with a few areas of marginal to fair coverage between miles 418 and 425 . Above mile 425 there is either marginal or no coverage.

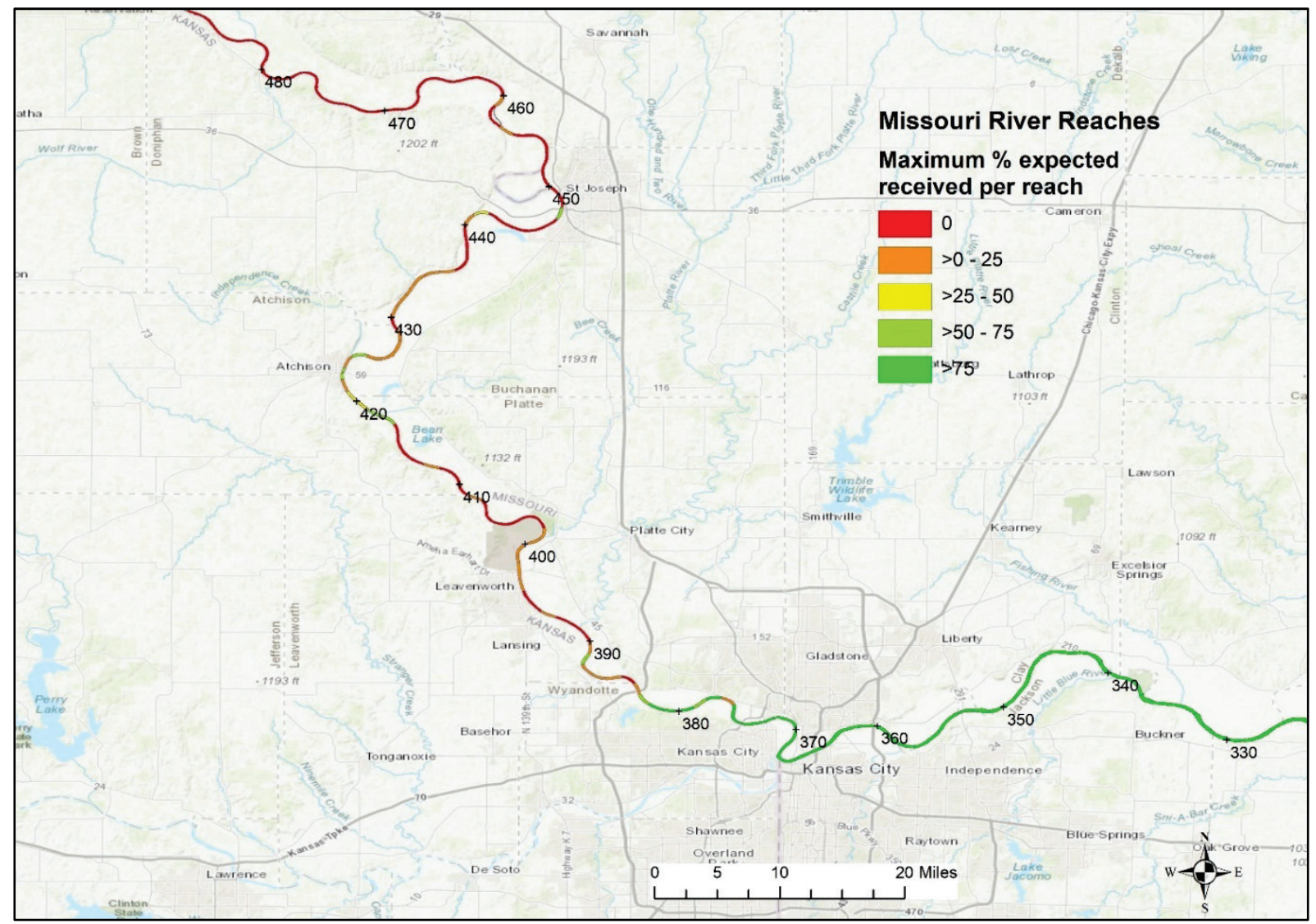

Figure 8. Aggregate coverage, mile 330-480. 
Figure 9, shows the percentage of expected position reports received for all vessels recorded within a given reach, with the $y$-axis truncated at $100 \%$ for clarity. In some reaches, the percentage of expected reports was well over $100 \%$ due to vessels that remained in the reach for significant amounts of time and due to vessels that transited a reach multiple times but were only counted as a single transit due to limitations in the methodology as described earlier.

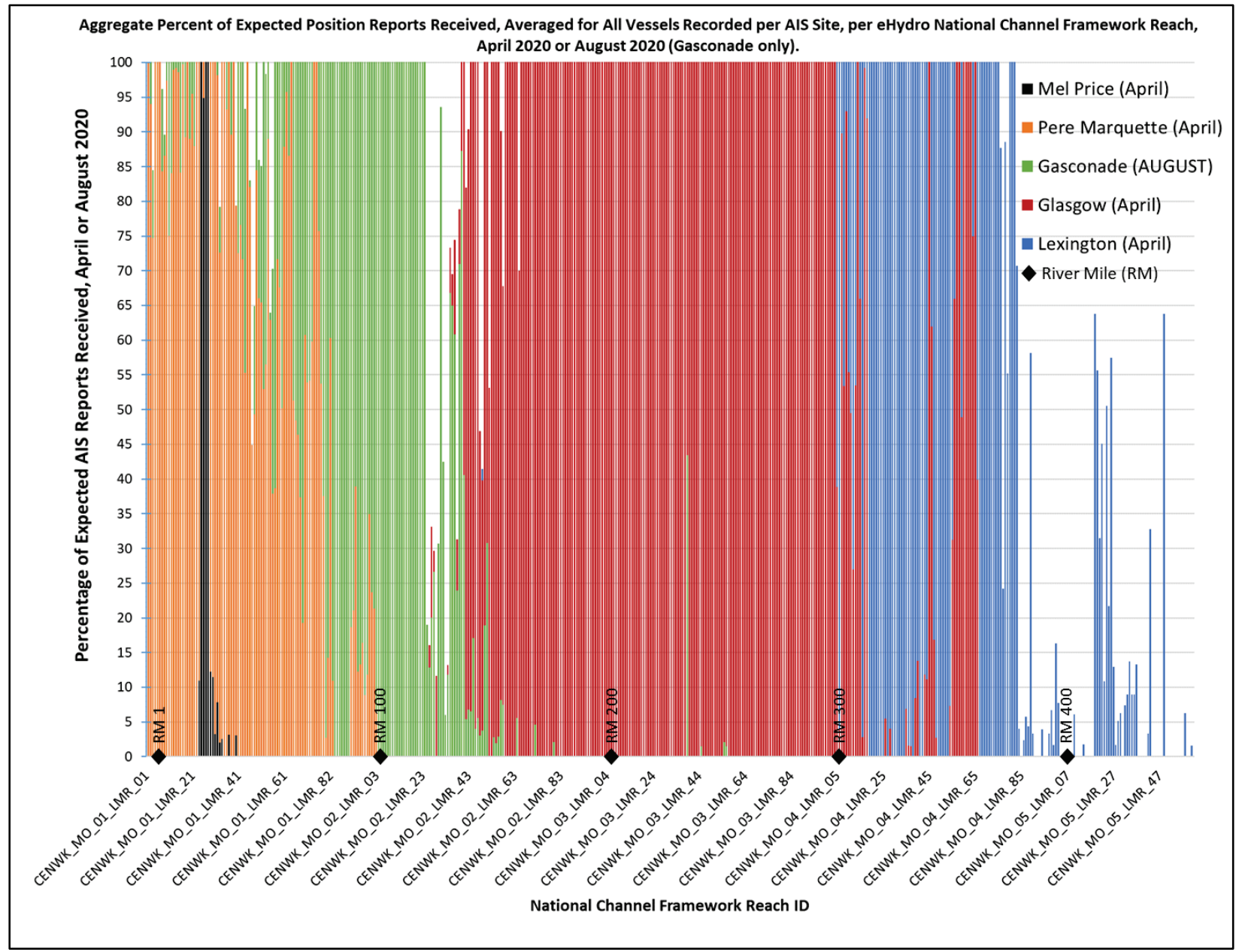

Figure 9. Aggregate percentage of expected position reports received by LOMAAIS sites in April 2020 and August 2020 (Gasconade site only). Graph truncated at 100\% of expected position reports.

CONCLUSIONS: The five sites examined in this analysis all appear to be performing as expected given the height of the antenna and the terrain, except for the Mel Price site, likely due to the low height of the antenna. The area above mile 380 is outside of the expected coverage area for the Lexington AIS site based on the antenna height (expected to be a maximum of $21 \mathrm{mi}[34 \mathrm{~km}]$ ). The initial analysis of the April 2020 data from the Gasconade site indicated potential problems, which was confirmed when it was noted that the Gasconade antenna was not placed at its optimal height until June 2020. Analysis of Gasconade data from August 2020 showed substantial improvement, and it now appears this site is performing as expected. The following areas have coverage of less than 50\% expected reports received: mile 48-49; mile 57; mile 125-136; mile 139; mile 150-151; mile 377; mile 383-418; above mile 420. 
RECOMMENDATIONS: USACE staff involved in Missouri River waterway management should determine if the coverage gaps coincide with critical areas. A critical area is an area where there is a need or anticipated need for AIS coverage to monitor vessel movements or transmit navigation safety information via AIS, such as virtual AtoN or geographic notices. The preliminary analysis presented in this CHETN could be expanded to include additional months or other years of data to provide a more complete picture of the coverage or to explore whether environmental conditions or other factors regularly affect coverage. Additional data should be collected aboard vessels that regularly transit the Missouri River to measure the reception of information onboard vessels as transmitted from LOMA AIS transceivers. Future research into coverage analysis is proposed to include vessel transit count through each reach, which can be used to normalize the expected number of position reports in each reach; possibly removing slow-moving vessels and vessels that operate only in a small number of reaches; and a radio frequency-based analysis of the expected coverage at each site (a calculation based on antenna height, terrain, vessel antenna height, and transmission power).

ADDITIONAL INFORMATION: This CHETN was prepared by Brian Tetreault, Brian.J.Tetreault@usace.army.mil, Marin M. Kress, Marin.M.Kress@usace.army.mil, (ORCiD 00000002-5835-5686), and Patricia DiJoseph, Patricia.K.DiJoseph@usace.army.mil, ERDC-CHL. Sincere appreciation is expressed to the LOMA team members (including L. Whitlow, B. Towne, J. Kilroy), and the USCG NAIS program. The study was funded by the USACE Navigation Systems Research Program. This technical note should be cited as follows:

Tetreault, Brian J., Marin M. Kress, and Patricia K. DiJoseph. 2022. AIS Data Case Study: Evaluating Reception of AIS Position Reports on the Missouri River by LOMA AIS Sites in April and August 2020. ERDC/CHL CHETNXI-58. Vicksburg, MS: US Army Engineer Research and Development Center. http://dx.doi.org/10.21079/11681/42980

\section{REFERENCES}

Asborno, M. I., S. Hernandez, M. Yves. 2020. Network Mapping of AIS Data to Characterize Inland Waterway Freight Transportation. Fayetteville, Arkansas: Maritime Transportation Research and Education Center, University of Arkansas. https://cpb-us-e1.wpmucdn.com/sites.uark.edu/dist/e/220/files/2020/07/Network-Mapping-of-AIS-Datato-Characterize-Inland-Waterway-Freight-Transportation.pdf

Dijoseph, P. K., K. N. Mitchell, B. J. Tetreault, and J. Marshall. 2019. Inland Marine Transportation System Travel Time Atlas via Automatic Identification System (AIS) Data: Ohio River, Upper Mississippi River, and Illinois River. ERDC/CHL TR-19-15. Vicksburg, MS: US Army Engineer Research and Development Center. https://apps.dtic.mil/sti/citations/AD1080408

ESRI. 2019. ArcMap 10.7.1. [software program]. Redlands, CA. https://support.esri.com/en/products/desktop/arcgisdesktop/arcmap/10-7-1

IALA (International Association of Marine Aids to Navigation and Lighthouse Authorities). 2008. Establishment of AIS as an Aid to Navigation: Report ID 1062. https://www.iala-aism.org/product/establishment-of-ais-as-an-aid-tonavigation-1062/

IEC (International Electrotechnical Commission). 2001. EC 61993-2: 2001-12 Maritime Navigation and Radiocommunication Equipment and Systems - Automatic Identification Systems (AIS) - Part 2: Class A Shipborne Equipment of the Universal Automatic Identification System (AIS) - Operational and Performance Requirements, Methods of Test and Required Test Results. https://www.iec.ch/index.htm 
ITU-R (International Telecommunications Union - Radiocommunication Sector). 2014. Recommendation ITU-R M.1371: Technical Characteristics for an Automatic Identification System Using Time Division Multiple Access in the VHF Maritime Mobile Frequency Band. https://www.itu.int/rec/R-REC-M.1371/en

Kress, M. M., B. J. Tetreault, K. N. Mitchell, M. Balazik, and M. C. Booton 2020. AIS Data: Real-Time Operation Support, Incident Investigations, and Waterway Use Analysis. ERDC/CHL CHETN-IX-53. Vicksburg, MS: US Army Engineer Research and Development Center. http://dx.doi.org/10.21079/11681/36395

Mitchell, K. N., and B. N. Scully. 2014. "Waterway Performance Monitoring via Automatic Identification System (AIS) Data." Transportation Research Record: Journal of Transportation 2426(1): 20-26. https://doi.org/10.3141/2426-03

Mitchell, K. N., P. K. DiJoseph, B. N. Scully, and M. M. Kress. 2020. Towing Vessel Delays and Barge Lane Navigability along the Houston Ship Channel, Texas. ERDC/CHL TR-20-1. Vicksburg, MS: US Army Engineer Research and Development Center. https://apps.dtic.mil/sti/pdfs/AD1089400.pdf

PIANC (The World Association for Waterborne Transport Infrastructure). 2019. Guidelines and Recommendations for River Information Services. InCom Working Group. Report Number 125/I-2019. https://www.pianc.org/publications/inland-navigation-commission/wg125-1

Scully, B., and K. N. Mitchell. 2015. Archival Automatic Identification System (AIS) Data for Navigation Project Performance Evaluation. ERDC/CHL CHETN-IX-40. Vicksburg, MS: US Army Engineer Research and Development Center. http://hdl.handle.net/11681/2066

Tabbert, C., J. Vest, A. Rhoads, D. Myers, T. Lauth, E. Brauer, J. Wallace, D. Gordon, and M. Kress. 2020. AIS Data Case Study: St. Louis Area Commercial Vessel Fleeting Activity and Potential River Training Structures. ERDC/CHL CHETN-IX-52. Vicksburg, MS: US Army Engineer Research and Development Center. http://dx.doi.org/10.21079/11681/36334

USACE (US Army Corps of Engineers). 2021. National Channel Framework (NCF) enterprise Geographic Information System. US Army Corps of Engineers Geospatial Open Data Portal. April 15, 2021. https://geospatialusace.opendata.arcgis.com/datasets/9227967a2748410983352b501c0c7b39

USCG (US Coast Guard). 2018. Navigation Center: Automatic Identification System Overview. http://www.navcen.uscg.gov/?pageName=AISmain

USCG Research and Development Center. 2014. Automatic Identification System (AIS) - AISMiner User Manual, (v4.4.0), November 2014. New London, CT.

US Code of Regulations. 2019. Title 33-Navigation and Navigable Waters. "Part 164-Navigation Safety Regulations." 33 C.F.R. § 164.46. Washington, DC. https://www.govinfo.gov/content/pkg/CFR-2019-title33-vol2/xml/CFR-2019title33-vol2-part164.xml

NOTE: The contents of this technical note are not to be used for advertising, publication or promotional purposes. Citation of trade names does not constitute an official 